PLEASE NOTE! THIS IS SELF-ARCHIVED VERSION OF THE ORIGINAL ARTICLE

To cite this Article: Rantanen, T. \& Toikko, T. (2017) The relationship between individualism and entrepreneurial intention - a Finnish perspective. Journal of Enterprising Communities 11:2, 289-306.

URL: http://www.emeraldinsight.com/doi/full/10.1108/JEC-10-2014-0021

DOI: 10.1108/JEC-10-2014-0021 
Rantanen, T. \& Toikko, T. (2017) The relationship between individualism and entrepreneurial intention - a Finnish perspective. Journal of Enterprising Communities 11:2, 289-306.

\title{
The relationship between individualism and entrepreneurial intention - a Finnish perspective
}

\author{
Teemu Rantanen \& Timo Toikko
}

\begin{abstract}
Purpose: This study analyzes the relationship between individualist values and entrepreneurial intentions. Previous surveys have shown that major national differences in entrepreneurial intentions can be observed within Europe and that part of this variation can be explained by cultural values, especially the individualism-collectivism dimension. However, previous findings about the relationship between individualism and entrepreneurship remain contradictory.

Research design and methods: This study is a micro-level analysis of the influence of individualistic values. The theoretical framework of the study is based on the theory of planned behavior (Ajzen, 1991; 2001) and theories of individualism advanced by Hofstede (1980) and Triandis and Gelfand (1998). The research data were gathered from a survey of Finnish students

$(N=725)$.

Findings: The results show that the relationship between cultural values and entrepreneurial intention is very complex. In contrast to Hofstede (1980), the study assumes individualism and collectivism to be two separate and independent dimensions of cultural values, both of which have a positive, indirect effect on entrepreneurial intention by way of subjective norms and perceived control.

Practical implications: Both individualist and collectivist values promote entrepreneurial intentions. From this point of view, general citizenship education, which supports the development of young people's cultural values, can be seen as a significant element in entrepreneurship education. This suggests an instance of holistic education, the aim of which is for individuals' autonomy and contestability to be combined with community and collective responsibility.

Originality/value: The analysis of Triandis and Gelfand (1998) has not been systematically utilized in the previous studies on entrepreneurial intentions. The findings of this study address not only the influence of psychological factors over entrepreneurial intentions, but also the impact of individualist and collectivist values. The results complement the results of previous studies.
\end{abstract}

\section{Introduction}

Economic globalization has raised the question about the importance of culture in entrepreneurship. Culture is a multidimensional phenomenon, but this study focuses only on its individualismcollectivism dimension. For example, according to the classic analysis of Hofstede (1980), individualism-collectivism is one of the key dimensions of culture. However, previous research has 
shown that the dependence between the individualism-collectivism dimension and entrepreneurship is both multi-level and complex. Individualism highlights an individual's autonomy and independence, and according to Lumpkin and Dress (1996), autonomy is a key factor of entrepreneurial orientation. It has also been shown that individualism is connected to innovation and long-term growth (Gorodnichenko and Roland, 2012). However, Tiessen (1997) has argued that while individualism leads to new venture creation and innovation, collectivist values are pivotal in allowing firms to leverage their resources. Kreiser et al. (2001) have argued that the relationship between individualist values and entrepreneurial orientation is curvilinear, that is, extreme levels of either individualism or collectivism diminish entrepreneurial behavior. According to those authors, depending on the context in which the firm operates, individualist values may act to both encourage and discourage risk-taking within entrepreneurial organizations.

This study focuses on entrepreneurial intention. From the perspective of entrepreneurship education and new venture creation, the concept of entrepreneurial intention plays a central role in the process of becoming an entrepreneur. Entrepreneurial intention research has expanded rapidly in recent years. At the same time, there have been efforts aimed at exploring new directions for intention research (Fayolle and Liñán, 2014). This study focuses on the relationship between individualism and entrepreneurial intention.

Scholars have recently emphasized a variety of explanatory models of entrepreneurship intention. In the Shapero-Krueger model, perceived desirability and propensity to act have been identified as variables explaining intention (Krueger et al., 2000). According to several studies, the theory of planned behavior (Ajzen, 1991, 2001) has been effective in explaining entrepreneurial intention and behavior (e.g. Liñán, 2008; Liñán and Chen, 2009; Goether et al., 2012; Moriano et al., 2012; Walker et al., 2013) as well as in assessing entrepreneurship education programs (e.g. Fayolle and Gailly, 2004; Fayolle et al., 2006; Weaver et al., 2012). In a large proportion of entrepreneurial intention studies, the explanatory model includes a variety of social and economic factors, such as social capital (Liñán and Santos, 2007; Chuluunbaatar et al., 2011; Goether et al., 2012).

According to a comparative Global Entrepreneurship Monitor (GEM) study, major national differences in entrepreneurial intention can be observed in Europe. This could be explained by a number of economic factors, for example, the level of economic development (Xavier et al., 2013). Noorderhaven et al. (2004) have shown that gross domestic product (GDP) per capita has a strong negative impact on self-employment. It has also been asked whether cultural factors exert influence 
on entrepreneurial attitudes and intentions (e.g. Lindsay, 2005). It has been argued that a "supportive” national culture will, all things being equal, increase the entrepreneurial potential of a country (Mueller and Thomas, 2001). In particular, the importance of individualist values is highlighted in terms of entrepreneurial intention (e.g. Mitchell et al., 2000; Liñán and Chen, 2009; Siu and Lo, 2013).

Some researchers have argued that entrepreneurial activities are based on the common effect of cultural values and social, political, and economic factors (e.g. Lee and Peterson, 2000). Fitzsimmons and Douglas (2005) particularly emphasize the impact of low per capita income, high individualism, and lower scores on Hofstede’s Uncertainty Avoidance Index (UAI). Mueller (2004) has also explained entrepreneurial potential in relation to gender, Hofstede's cultural dimensions, and economic development (GDP per capita).

According to Tiessen (1997), there are two main streams of research on the effects of individualismcollectivism on entrepreneurship: the macro stream associates both individualism and collectivism with the national level of economic growth and innovation. The micro stream identifies individuals and the individual characteristics that influence intentions. This paper commences with a macro review of the relationship between the individualism-collectivism index by Hofstede (Hofstede Centre, 2013) and entrepreneurial intentions based on a GEM study (Xavier et al., 2013). The more detailed nature of the relationship between individualism and entrepreneurial intention is analyzed by testing four different explanatory models. This micro-level analysis focuses on young people in Finland, where entrepreneurial intention is at a low level (Xavier et al., 2013), even though entrepreneurship education has been strongly emphasized over the past ten years (e.g. Ministry of Education, 2004). Thus, it is reasonable to analyze the cultural factors that may affect this situation.

This study is based on three starting points. First, the concepts of entrepreneurial intention and individualism are defined. Second, the relationship between individualism and entrepreneurial intention is analyzed using country-level comparisons based on the overall perspective of Hofstede’s indexes (The Hofstede Centre, 2014) and the concept of individualism by Singelis et al. (1995). Third, the indirect impact of individualism is analyzed on the basis of a variety of psychological variables, employing the theory of planned behavior (Ajzen, 1991) as a starting point. The research design was constructed from the above-mentioned starting points, such that the main focus is on the relationship between individualism and entrepreneurial intention. The study examines four hypotheses, which are tested in the Finnish survey data. 


\section{A Theoretical Background and Comparative Review}

The concepts of entrepreneurial intention and individualism

In the theory of planned behavior (Ajzen, 1991), the term intention refers to specific action-intention - an intention to behave in a certain way or to perform a certain act. However, in the context of attitude studies, intentions have been understood in different ways, which are related not just to the actual intention, but also to the desirability of the object and how likely an individual believes his/her attainment of the object to be (Armitage and Conner, 2001). Often, entrepreneurial intention means a person's concrete plan or serious intention to start a firm in the near future. In terms of young people who do not yet have clear career plans, the concept can also refer to a person's general desire or aspiration to become an entrepreneur.

The concepts of individualism and collectivism have been variously defined. According to the Hofstede Centre (2014), individualism is one dimension of cultural values (the individualismcollectivism index) and can be defined as a preference for a loosely-knit social framework in which individuals are expected to take care only of themselves and their immediate circle. Hofstede's (1980) classical analysis assumes that individualism and collectivism are opposites. In contrast, Singelis et al. (1995) examined these as separate dimensions and made a distinction between two forms of individualism and two forms of collectivism. Horizontal individualism includes the conception of an autonomous individual with an emphasis on equality while vertical individualism accepts inequality and competition between individuals. Similarly, Singelis et al. (1995) distinguished between two forms of collectivism: horizontal collectivism emphasizes equality while vertical collectivism indicates hierarchy.

Schimmack et al. (2005) discussed the two main approaches in studies of individualism. The tradition of applying Hofstede is based on Hofstede's original concepts and aims to analyze the cultural differences between nations by using the individualism-collectivism index. In contrast, the goals of the measuring individualism approach are to develop new measures of individualism and to examine whether the within-nation variability in individualism and collectivism is related to dependent variables. In particular, Triandis and Gelfand's (1998) concepts of individualism and collectivism are a useful starting point for this kind of within-nation analysis whereby individualism is considered as an individual-level variable. This study combined a country-level comparative review and an 
individual-level empirical analysis of the impact of individualism; it therefore used Hofstede's index as well as the conceptual model of Triandis and Gelfand (1998).

The relationship between collectivism and entrepreneurship can also be studied from a community perspective (see for instance Dana, 1997). Entrepreneurship has been studied, for example, among Eskimos in Alaska (Dana, 1995), indigenous peoples in Australia (Lindsay, 2005), Amish communities in America (Kraybill, Nolt and Wesner, 2011) and Sámi people in Finland (Dana and Light, 2011). According to Kraybill, Nolt and Wesner (2011) the Amish community includes various forms of socio-cultural capital (human, cultural, social, religious, and symbolic), which support entrepreneurs' success. Their performance is considerably better than that of other American small enterprises. In the same way, also Dana and Light (2011) have showed that Sámi reindeer herders are not only financially motivated in their entrepreneurship but they also emphasize the maintaining of the cultural tradition. Reindeer herding can be called community-based entrepreneurship which is passed from adults to children as cultural capital.

On the whole, the entrepreneurial intention indeed gets different significances in the individualist and collectivist cultures. In the individualist culture, the entrepreneurship provides the opportunity for autonomy and economic success whereas in the collectivist culture the motives of the entrepreneurship are more manifold and also are connected to the cultural tradition and community.

\section{Comparative analysis in European Union countries}

The relationship between individualism and entrepreneurial intention is subsequently examined on the basis of present country-level statistics. Figure 1 shows Hofstede’s individualism-collectivism index (Hofstede Centre, 2014) and entrepreneurial intention based on GEM research (Xavier et al., 2013) in European Union (EU) countries. 


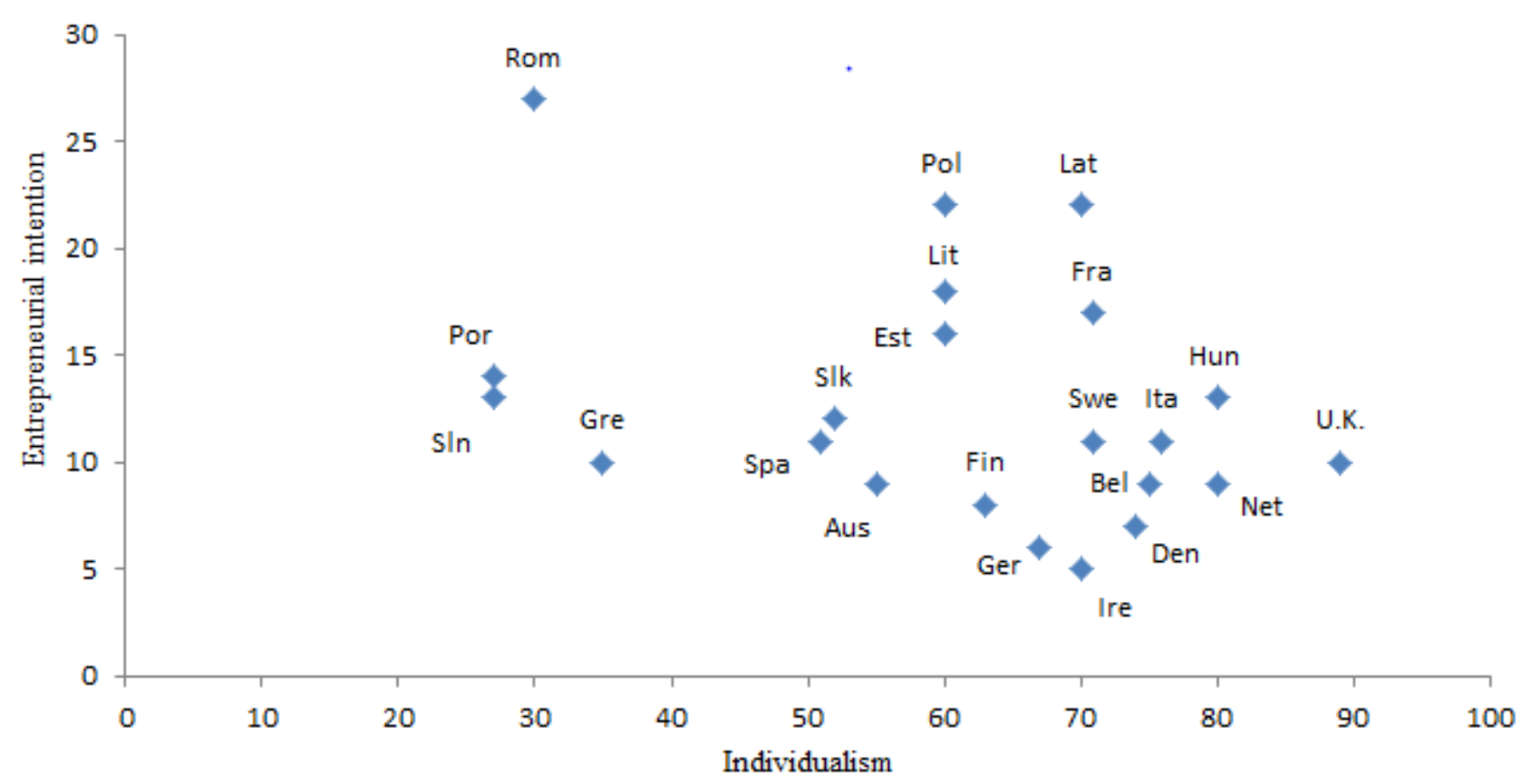

Figure 1: Level of entrepreneurial intentions as a function of individualism in the countries of the European Union (sources: GEM, Hofstede Centre).

According to the individualism-collectivism index, four EU countries are clearly collectivist (Portugal, Slovenia, Romania, and Greece). Spain and Slovakia are positioned in the middle of the individualism-collectivism scale, and the remaining EU countries can be classified as individualistic (Hofstede Centre, 2014). According to GEM research, the EU countries with the highest entrepreneurial intention are Romania, Latvia, and Poland (Xavier, 2013). Of these, Romania is seen as collectivist, and Latvia and Poland are each seen as individualist. Intention is at its lowest level in Ireland, Germany, Denmark, and Finland (Xavier, 2013), which are all individualistic countries. On the basis of this country-level comparison, it would seem that in many individualistic countries, entrepreneurial intention is lower than in countries with a lower level of individualism. However, the relationship is not clear-cut, and there are many exceptions.

According to GEM research, national differences are explained by the level of economic development. Six EU countries (Estonia, Hungary, Latvia, Lithuania, Poland, and Romania) are efficiency-driven, and the remainder are innovation-driven (Xavier et al., 2013). Much of the variation in entrepreneurial intention can be explained by the level of economic development. Thus, the relationship between individualism and entrepreneurial intention is also necessary in order to separately consider innovation-driven $(\mathrm{N}=16)$ and efficiency-driven $(\mathrm{N}=6)$ countries. According to Figure 2, the negative relationship between individualism and entrepreneurial intention can be seen 
in both groups of countries. Particularly in the group of efficiency-driven countries, intention is the highest in the country with the lowest level of individualism and vice versa. In the group of innovation-driven countries, the results seem similar from a general viewpoint, but they are not as clear as those among the efficiency-driven countries.

a) Innovation-driven countries $(\mathrm{N}=16)$

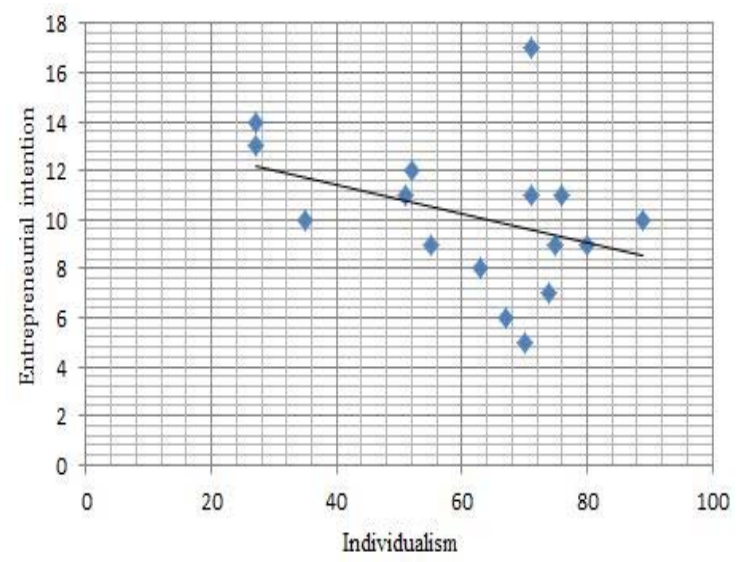

b) Efficiency-driven countries $(\mathrm{N}=6)$

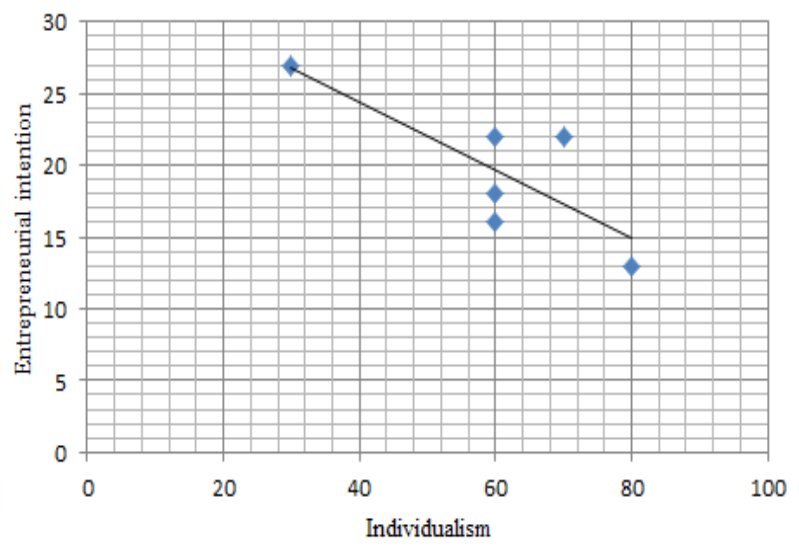

Figure 2: Entrepreneurial intention as a function of individualism in countries of the European Union. a) Innovationdriven countries ( $\mathrm{N}=16)$, b) Efficiency-driven countries $(\mathrm{N}=6)$ (sources: GEM, Hofstede Centre).

The analysis of Figure 2 can be deepened by paying attention to the different forms of individualism. France is the only innovation-driven country in the EU where entrepreneurial intention is at the same level as that in efficiency-driven countries. This exception could in turn be explained by a conceptual distinction between vertical and horizontal individualism: France is a typical example of vertical individualism (Triandis and Gelfand, 1998, p. 119). Given that vertical individualism highlights independence and the importance of competition, it is natural to suppose that it also has a connection with the desire to become an entrepreneur. Accordingly, intention is at a very low level in all Nordic countries (Sweden, Denmark, and Finland), all of which are typical examples of horizontal individualism.

Indirect effect of individualism: The theory of planned behavior

Some researchers have assumed that the impact of individualism is indirect and can be described as a two-stage process. Mitchell et al. (2000) have shown that individualism has a complex, indirect effect on decision-making in venture creation via different cognitive scripts. According to Lindsay's 
(2005) model, cultural values influence entrepreneurial attitudes, and furthermore, attitudes influence entrepreneurial behavior (see Figure 3).

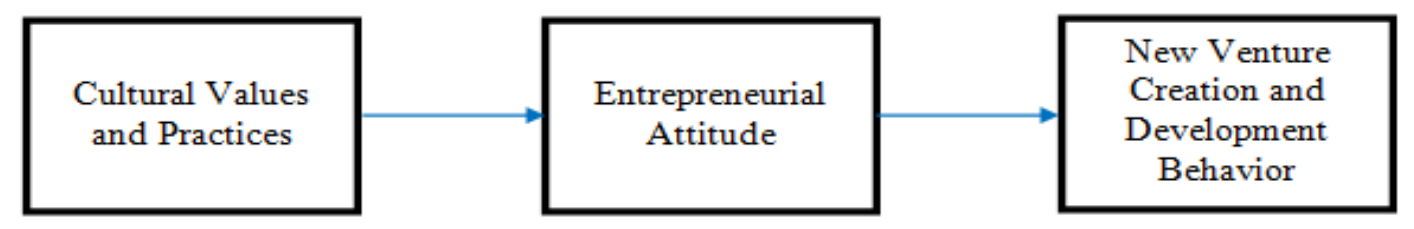

Figure 3: Cultural model of entrepreneurial attitude and entrepreneurial behaviour (Lindsay, 2005).

The concept of attitude is also multidimensional and does not have a single consistent definition. Typically, attitude is defined as a psychological tendency that is expressed by evaluating a particular entity within some dimension (Eagly and Chaiken, 1993). In traditional social psychology, attitude is understood, in particular, as a general valuation. However, Ajzen's $(1991,2001)$ starting point is that attitudes always take place in a certain context, so specific attitudes (as opposed to general attitudes) toward a specific activity must be studied. Attitude is also variously understood in entrepreneurial intention studies. For example, the measure of personal attitude by Liñán and Chen (2009) is related to personal career choices (e.g. "how attractive a career as an entrepreneur is for a respondent”). In contrast, the GEM survey examined the general appreciation of respondent entrepreneurs.

In Ajzen's concept of attitude, whereby the subject of the attitude is the individual's own behavior, is fundamentally flawed: when each activity has its own related attitude, then the concept of the attitude becomes narrower, and its explanatory power simultaneously decreases. Such an interpretation of attitude also deviates from the concept of attitude expressed in traditional attitude theory. Therefore, in this study, Ajzen's concept of attitude is replaced with a general concept of attitude.

According to the theory of planned behavior, behavioral intentions are caused not only by attitudes, but also by two other components: subjective norms and perceived behavioral control (Ajzen, 1991, p. 182). Thus, young people's entrepreneurial intentions are influenced by their personal appreciation of entrepreneurship, the expectations of their closest circle, and their own perceptions of their capacity as entrepreneurs. By combining the theory of planned behavior and the idea of the indirect impact of individualism and collectivism, we can construct a model that assumes that entrepreneurial attitude, subjective norms, and perceived control influence entrepreneurial intention. Further, individualism and collectivism influence all factors relating to intention (i.e. entrepreneurial attitude, subjective norms, and perceived control). 
Ajzen's (1991, 2001) concept of subjective norm represents the belief that one's close peers value the desirability of a particular behavior. From the perspective of the subjective norm, the main significance is the social context with which the young person associates his/her future business activity and whose valuations the young person considers to be important in that context. In the case of young people, subjective norms may refer to, for example, the expectations and wishes of parents and peer groups.

Perceived behavioral control (Ajzen 1991, 2001) is related to how a young person evaluates his/her own personal capacity to endure the different duties and responsibilities associated with entrepreneurial activities and setting up an enterprise. The concept is based on Bandura's (1982) social learning theory and the concept of perceived self-efficacy. Bandura (1982, p. 140) also talked about expected outcomes, which in the context of entrepreneurship refer to how firmly young people believe they can succeed as entrepreneurs. According to previous entrepreneurial intention research, perceived self-efficacy and outcome expectations are very strongly correlated with each other among young people (Rantanen \& Toikko, 2013b). Therefore, this study focuses on perceived control, which is a combination of these two variables. The concept refers to people's self-beliefs about being able to cope and succeed as entrepreneurs.

Some researchers have suggested that it would be useful to examine the impact of culture on entrepreneurial intention as a moderating effect (Urbano, 2004, p. 99; Liñán and Chen, 2009; Siu and Lo, 2013). Liñán and Chen (2009) have argued that the influence of entrepreneurial attitudes, subjective norms, and perceived behavioral control depends on the national level of individualism. According to them, the relative importance of entrepreneurial attitude is stronger in more individualistic countries, and the effects of perceived behavior control and subjective norms are stronger in less individualistic countries. In addition, the model of Liñán and Chen (2009) assumes that the effect of subjective norms is indirect. Thus, the model considers four relations: norm-attitude, norm-control, attitude-intention, and control-intention.

\section{Hypotheses}

The relationship between individualism and entrepreneurship can been analyzed on a country level (cross-cultural analysis, national growth, etc.), an organizational level (organizational culture, entrepreneurial orientation, etc.), an individual level (cultural values, attitudes, intentions, etc.), or by combining different levels (e.g. a cross-cultural analysis of individual intentions). This study focuses 
on the individual-level and the Finnish context in particular. According to GEM research (Xavier et al., 2013, p. 21), Finland is an innovation-driven economy with a low level of entrepreneurial intention. Contrastingly, however, in Finland the status of successful entrepreneurs is the highest in the European Union. This study thus asks: What is the relationship between individualism and entrepreneurial intention among young Finnish people?

On the basis of previous studies and cross-cultural comparison, at least four alternative models on the relationship between entrepreneurial intention and individualism can be constructed. First, it can be assumed that there is direct dependence. Further, and congruent with Hofstede (1980), it could be assumed that individualism and collectivism are opposites, i.e. two extremes of the same dimension. Moreover, according to the comparative analysis of EU countries, the individualism-intention dependence is negative. The first hypothesis assumes that collective values will increase the desire to become an entrepreneur, and correspondingly, individualist values make entrepreneurship less attractive:

H1: (a) Individualism correlates negatively with entrepreneurial intention, and (b) collectivism correlates positively with entrepreneurial intention among young Finnish people.

The second model is based on the distinction between horizontal and vertical individualism (Singelis et al., 1995; Triandis and Gelfand, 1998). It can be assumed that entrepreneurial intention is especially related to vertical individualism, which emphasizes individuality and competition, but not to horizontal individualism, which stresses the equality of human beings:

H2 (a) Vertical individualism has a positive impact, and (b) horizontal individualism has a negative impact on entrepreneurial intention among young Finnish people.

The third model is based on the theory of planned behavior (Ajzen, 2001) and on the assumption that the impact of individualist and collectivist values is indirect (e.g. Lindsay, 2005). In particular, it is assumed that cultural values have a positive impact on all the elements of intention:

H3: The relationship between cultural values (individualism and collectivism) and entrepreneurial intention is indirect among young Finnish people. Especially, (a) subjective norms, (b) perceived control, and (c) the entrepreneurship attitude positively depend on cultural values.

Fourth, on the basis of the analysis of Liñán and Chen (2009), a hypothesis can be constructed in relation to the comparison between young people with a high level of individualism and those with a low level of individualism. 
H4: (a) Subjective norms exert a stronger effect on attitude and perceived control among young Finnish people with low individualism; (b) the relative effect of attitude on entrepreneurial intention is stronger among young Finnish people with high individualism;(c) the effect of perceived control is stronger among young Finnish people with low individualism.

\section{Methods and Sample}

This study considers the importance of individualism in the Helsinki-Uusimaa region in Southern Finland. The population of the region is 1.6 million, which accounts for $29 \%$ of the total Finnish population (Official Statistics of Finland, 2014). Uusimaa has a service-dominant economic structure. Nonetheless, many large industrial companies are also registered and have their headquarters there. Uusimaa also accounts for $48.4 \%$ of the country's revenue (Ministry of Employment and the Economy 2012, p. 152). In this context, issues concerning young people's entrepreneurial intentions in the Helsinki-Uusimaa region are also important from the perspective of the wider national economy. Notwithstanding, the results of this study cannot be generalized to all of Finland.

The data was collected using an electronic form in January and February 2013 from respondents in their second year of secondary education, mostly 17 and 18-year-old students. In Finland, 90\% of 1618-year-olds study in either an upper secondary school or a vocational high school (City of Helsinki, 2009, p. 15). After their eighteenth birthday, there is much more variation in young people's situations. Therefore, from the perspective of the sample's comprehensiveness, 17-18-years-olds are an optimal target group. The sample included a total of 725 respondents from six upper secondary schools and six vocational schools (Table 1).

Table 1: Respondents (N=725).

\begin{tabular}{llcc}
\hline Background variable & Group & $\mathrm{N}$ & $\%$ \\
\hline Gender & Female & 363 & 50.1 \\
& Male & 362 & 49.9 \\
\hline School & Upper secondary school & 432 & 60.0 \\
& Vocational school & 288 & 40.0 \\
\hline Language & Finnish & 659 & 90.9 \\
& Swedish & 66 & $9.1^{1}$ \\
\hline City & Helsinki (Metropolitan Area) & 496 & $68.4^{2}$ \\
& Other Uusimaa & 229 & 31.6 \\
\hline Total & - & 725 & 100 \\
\hline
\end{tabular}

${ }^{1} 8.4 \%$ in Uusimaa`s overall population, ${ }^{2} 68.8 \%$ in Uusimaa’s overall population. (Official Statistics of Finland, 2014). 
The schools were chosen to ensure the best possible representativeness of the data in relation to the wider population of Uusimaa (the criteria for the selection of the schools were regional coverage and representativeness, the schools' language, and their representativeness in relation to the field of education). An examination of the material shows that this was successful. The response rate was $46 \%$ due to some practical organizational issues, such as students' work placements and schedulerelated problems. However, it can be assumed that these did not result in significant systematic errors in the study model.

The analysis was performed using statistical methods. Sum variables were formed by factor analysis (principal axis factoring, Varimax with the generalized Kaiser Normalization). Reliabilities were calculated using Cronbach's alpha, and the normality of the distributions was examined using the Kolmogorov-Smirnov test. The effect of the background variables was analyzed using a t-test. The importance of cultural values was examined using Pearson's correlation coefficient and linear regression analysis. In the case of regression analyses (Tables 3 and 4), the validity of the conditions were checked (the normality of the residuals' distributions, the linearity condition, and the multi-colinearity between the independent variables/VIF coefficients), and the background variables (gender, entrepreneurial family) were examined as dummies. The model by Liñán and Chen (2009) was tested by dividing the data into quartiles in relation to individualism and by comparing the first and fourth quartiles (i.e. respondents with the lowest and highest values of individualism). For the analysis of the differences between these groups, the t-test and Fisher's F-test were utilized.

\section{Measures}

The questionnaire contained a total of 89 questions, the majority of which were Likert-type scale items (1=Strongly disagree to 5=Strongly agree). As per Armitage and Conner's (2001) metaanalyses, the variables of the theory of planned behavior were examined using a number of different measures. In this study, the questions relating to entrepreneurial intentions, entrepreneurship attitude, subjective norms, and perceived control were based on a previous attitude survey among young Finnish people (Rantanen \& Toikko 2013a; 2013b). A measure of entrepreneurial intentions was formed from four questions, which were connected not only to the actual intention ("My aim is to become an entrepreneur in the future," and "I am going to make a living as an entrepreneur"), but also to entrepreneurial willingness ("If I could choose freely, I'd rather be an entrepreneur than an employee") and assessed how likely a career choice of entrepreneurship would be ("For me, entrepreneurship is a probable career choice”). 
Questions about entrepreneurial attitude were related to the general perception of entrepreneurship and not to behavioral attitude. These questions were associated with the value of entrepreneurial work and entrepreneurs (e.g. "Entrepreneurs are ideal citizens”) as well as their societal significance (e.g. "Entrepreneurs play a key role in the success of the society"). The measure of perceived control contained issues relating to young people’s confidence in their own abilities to act (e.g. "I believe I would have the qualifications to work as the manager of a small enterprise”) and succeed as an entrepreneur (e.g. "I believe I could succeed as an entrepreneur"). Questions about their subjective norms related to the normative expectations of parents, friends, their professional field, and their close environment in general. Sum variables were construed using factor analysis.

The measure of cultural values was based on the individualism-collectivism scales offered by Triandis and Gelfand (1998). The original measure contained two types of individualism and two types of collectivism, but this study also examined the combined variables of individualism and collectivism. These variables were construed using factor analysis, which explains $32.2 \%$ of the variation. Factor 1 contained questions concerning horizontal and vertical collectivism (8 statements), and factor 2 contained questions relating to horizontal and vertical individualism (8 statements). The constructed variables of individualism and collectivism were not significantly correlated with each other $(\mathrm{R}=-$ 0.012). In contrast, however, the correlation between horizontal and vertical individualism $\left(\mathrm{R}=0.334^{* * *}\right)$ was significant, as was the correlation between horizontal and vertical collectivism $\left(\mathrm{R}=0.566^{* * *}\right)$. Therefore, this study supports a two-dimensional model of individualism and collectivism. In the four-dimensional model, it can be seen that the dimensions are not independent of each other.

The reliabilities of entrepreneurial intention, subjective norms, and perceived control were good, but the reliabilities of horizontal individualism and vertical collectivism were relatively low (Table 2). The reliabilities of cultural factors were close to those demonstrated in the original study of Triandis and Gelfand (1998). The distributions of the constructed variables were roughly normal.

Table 2: Variables and their reliabilities.

\begin{tabular}{lccccc}
\hline & $\mathrm{N}$ & Items & $\begin{array}{c}\text { Cronbach’s } \\
\text { alpha }\end{array}$ & Mean & Sd \\
\hline Entrepreneurial intention & 723 & 4 & 0.899 & 2.73 & 1.00 \\
Entrepreneurship attitude & 722 & 4 & 0.705 & 3.61 & 0.63 \\
Subjective norm & 723 & 5 & 0.820 & 2.91 & 0.82 \\
Perceived control & 723 & 7 & 0.933 & 3.30 & 0.94 \\
Individualism & 724 & 8 & 0.719 & 3.45 & 0.59 \\
Collectivism & 724 & 8 & 0.796 & 4.04 & 0.59 \\
\hline Horizontal individualism & 724 & 4 & 0.609 & 3.79 & 0.62
\end{tabular}




\begin{tabular}{llllll} 
Horizontal collectivism & 724 & 4 & 0.734 & 4.22 & 0.66 \\
Vertical individualism & 724 & 4 & 0.719 & 3.11 & 0.81 \\
Vertical collectivism & 724 & 4 & 0.668 & 3.86 & 0.67 \\
\hline
\end{tabular}

The background variables examined respondents' gender, school (upper secondary school, vocational school), and any entrepreneurial history in the family ("Is either of your parents or other member of your family an entrepreneur?”).

\section{Results}

The data shows some of the differences between the various groups of respondents. Entrepreneurial intention was higher among men than women $(\mathrm{t}=3.94 * * *)$, and an entrepreneurial family background had a positive impact on intention $\left(\mathrm{t}=3.97^{* * *}\right)$. In contrast, there was no significant difference between the types of school (upper secondary school, vocational school; $\mathrm{t}=1.88$ ).

Most of the respondents agreed with the questions on horizontal individualism. For example, 71.1\% of respondents agreed with "My personal identity, independent of others, is very important to me" only 3.6\% disagreed with the statement. In contrast, the respondents were not as consensual on the statements relating to vertical individualism. For example, $25.7 \%$ of respondents took the view that "Winning is everything," and $45.2 \%$ of respondents agreed with "Competition is a law of nature." According to the results, the cultural values among young Finnish people are quite collective. For example, $91.7 \%$ of respondents agreed with the statement "The well-being of my friend is important to me." Similarly, $75.6 \%$ of respondents thought that "Family members should stick together, no matter what sacrifices are required.”.

In addressing the hypotheses, we can first examine the correlations between cultural values and entrepreneurial intention. Hypothesis 1 is only partially valid: both individualism $\left(\mathrm{R}=0.276^{* * *}\right)$ and collectivism $\left(\mathrm{R}=0.124^{* * *}\right)$ correlate positively with entrepreneurial intention. Also, according to the regression model, they have a positive and significant impact on entrepreneurial intentions (Table 4, regression model 1). This result is contrary to Hofstede's one-dimensional model: from the perspective of entrepreneurial intention, individualism and collectivism are not opposites. However, this result helps us understand previous contradictory findings regarding the relationship between the individualism-collectivism dimension and entrepreneurship. 
The different forms of individualism and collectivism can also be examined (Hypothesis 2). All of the forms correlated with entrepreneurial intention (H-I: $\mathrm{R}=0.229 * * * ; \mathrm{H}-\mathrm{C}: \mathrm{R}=0.127 * * ; \mathrm{V}-\mathrm{I}$ : $\mathrm{R}=0.224 * * * ; \mathrm{V}-\mathrm{C}: \mathrm{R}=0.093^{*}$ ). According to the regression analysis (Table 3), vertical individualism, horizontal individualism, and horizontal collectivism can significantly explain intention. As expected, the beta coefficient of vertical individualism is the highest, however, the dependence between horizontal individualism and entrepreneurial intention is also positive. Therefore, the second model has not been supported.

Table 3: Regression analysis, four-dimensional models (hypothesis 2).

\begin{tabular}{lcccccc}
\hline & \multicolumn{3}{c}{ regression model 1 } & \multicolumn{3}{c}{ regression model 2 } \\
\hline & $\mathrm{B}$ & $\mathrm{SD}$ & (stand.) Beta & $\mathrm{B}$ & $\mathrm{SD}$ & (stand.) Beta \\
\hline (constant) & -.177 & .335 & - & -.192 & .328 & - \\
Horizontal individualism & .245 & .061 & $.151^{* * *}$ & .244 & .061 & $.150^{* * *}$ \\
Horizontal collectivism & .269 & .066 & $.177^{* * *}$ & .260 & .055 & $.171^{* * *}$ \\
Vertical individualism & .211 & .047 & $.170^{* * *}$ & .211 & .047 & $.170^{* * *}$ \\
Vertical collectivism & -.015 & .064 & -.010 & - & - & - \\
Gender & .343 & .072 & $.171^{* * *}$ & .343 & .072 & $.172^{* * *}$ \\
Entrepreneurial family & .248 & .077 & $.113^{* *}$ & .247 & .077 & $.113^{* *}$ \\
\hline $\mathrm{F}$ & & $18.7 * * *$ & & & $22.5 * * *$ & \\
$\mathrm{R}^{2}$ & & .136 & & & .136 & \\
\hline
\end{tabular}

Hypotheses 3 and 4 are based on the theory of planned behavior (Ajzen 1991, 2001); which assumes that entrepreneurial intention depends on attitude, subjective norms, and perceived behavioral control. The results show that young Finnish people have a very positive attitude toward entrepreneurship. For example, $37.7 \%$ of respondents agreed with the statement "Entrepreneurs are ideal citizens" while $12.2 \%$ disagreed. In contrast, the subjective norms variable was relatively low. Only $26.8 \%$ of the respondents agreed with the statement "My close environment encourages me towards entrepreneurship" - 36.8\% disagreed. Young people’s trust in their own ability to work and succeed as entrepreneurs was a little stronger than subjective norms. 
The linear regression analysis showed that subjective norms and perceived control explain entrepreneurial intention very well. According to the analysis, there is no positive dependence between entrepreneurial attitude and entrepreneurial intentions, in fact, quite the contrary. The Beta coefficients of individualism and collectivism were not significant in the first regression model (Table 4, regression model 2). As per the second regression model (Table 4, regression model 3), individualism had a small direct impact $(\mathrm{p}=0.050)$ on entrepreneurial intentions.

Table 4: Regression analyses (hypotheses 1 and 3).

\begin{tabular}{|c|c|c|c|c|c|c|c|c|c|c|c|c|}
\hline & \multicolumn{3}{|c|}{ Regression model 1} & \multicolumn{3}{|c|}{ Regression model 2} & \multicolumn{3}{|c|}{ Regression model 3} & \multicolumn{3}{|c|}{ Regression model 4} \\
\hline & B & Sd & $\begin{array}{c}\text { Beta } \\
\text { (stand.) }\end{array}$ & B & Sd & $\begin{array}{c}\text { Beta } \\
\text { (stand.) }\end{array}$ & B & Sd & $\begin{array}{c}\text { Beta } \\
\text { (stand.) }\end{array}$ & B & Sd & $\begin{array}{c}\text { Beta } \\
\text { (stand.) }\end{array}$ \\
\hline (constant) & -.022 & .327 & - & -.135 & .225 & - & -.232 & .172 & - & -.029 & .138 & - \\
\hline Individualism & .434 & .060 & $.253 * * *$ & .079 & .042 & .046 & .082 & .042 & $.048 *$ & - & - & - \\
\hline Collectivism & .253 & .061 & $.149 * * *$ & -.036 & .042 & -.021 & - & - & - & - & - & - \\
\hline $\begin{array}{l}\text { Subjective } \\
\text { norm }\end{array}$ & - & - & - & .685 & .039 & $.560 * * *$ & .681 & .038 & $.557 * * *$ & .684 & .038 & $.560 * * *$ \\
\hline $\begin{array}{l}\text { Perceived } \\
\text { control }\end{array}$ & - & - & - & .340 & .034 & $.320 * * *$ & .338 & .033 & $.318^{* * *}$ & .351 & .033 & $.330 * * *$ \\
\hline $\begin{array}{l}\text { Entrepreneur- } \\
\text { ship attitude }\end{array}$ & - & - & - & -.104 & .041 & $-.066 *$ & -.117 & .040 & $-.074 * *$ & -.109 & .040 & $-.069 * *$ \\
\hline Gender & .326 & .071 & $.163^{* * *}$ & .024 & .048 & .012 & - & - & - & - & - & - \\
\hline $\begin{array}{l}\text { Entrepreneu- } \\
\text { rial family }\end{array}$ & .243 & .077 & $.111 * *$ & -.042 & .052 & -.019 & - & - & - & - & - & - \\
\hline $\mathrm{F}$ & \multicolumn{3}{|c|}{$26.4 * * *$} & \multicolumn{3}{|c|}{$170.4 * * *$} & \multicolumn{3}{|c|}{$298.1 * * *$} & \multicolumn{3}{|c|}{$394.6 * * *$} \\
\hline $\mathrm{R}^{2}$ & \multicolumn{3}{|c|}{.129} & \multicolumn{3}{|c|}{62.6} & \multicolumn{3}{|c|}{62.5} & \multicolumn{3}{|c|}{62.3} \\
\hline
\end{tabular}

\begin{tabular}{|c|c|c|c|c|c|c|c|c|c|c|c|c|}
\hline & \multirow{2}{*}{\multicolumn{3}{|c|}{$\begin{array}{l}\text { Independent variable: } \\
\text { Subjective norm }\end{array}$}} & \multirow{2}{*}{\multicolumn{3}{|c|}{$\begin{array}{l}\text { Independent variable: } \\
\text { Perceived control }\end{array}$}} & \multicolumn{6}{|c|}{ Independent variable: Entrepreneurial attitude } \\
\hline & & & & & & & \multicolumn{3}{|c|}{ Regression model 1} & \multicolumn{3}{|c|}{ Regression model 2} \\
\hline & B & Sd & $\begin{array}{l}\text { (stand.) } \\
\text { beta }\end{array}$ & B & Sd & $\begin{array}{l}\text { (stand.) } \\
\text { beta }\end{array}$ & B & Sd & $\begin{array}{l}\text { (stand.) } \\
\text { beta }\end{array}$ & B & Sd & $\begin{array}{l}\text { (stand.) } \\
\text { beta }\end{array}$ \\
\hline (constant) & .505 & .264 & - & -.174 & .297 & - & 1.604 & .206 & $(* * *)$ & 1.600 & .202 & $(* * *)$ \\
\hline Individualism & .316 & .049 & $.225^{* * *}$ & .478 & .055 & $.296 * * *$ & .223 & .038 & $.206 * * *$ & .223 & .038 & $.206 * * *$ \\
\hline Collectivism & .270 & .049 & $.193 * * *$ & .393 & .055 & $.245^{* * *}$ & .297 & .038 & $.275 * * *$ & .298 & .038 & $.276 * * *$ \\
\hline Gender & .264 & .057 & $.162^{* * *}$ & .358 & .065 & $.190 * * *$ & -.005 & .045 & -.004 & - & - & - \\
\hline $\begin{array}{l}\text { Entrepreneu- } \\
\text { rial family }\end{array}$ & .329 & .062 & $.183^{* * *}$ & .205 & .070 & $.099 * *$ & .134 & .049 & $.097 * *$ & .135 & .049 & $.097 * *$ \\
\hline $\mathrm{F}$ & \multicolumn{3}{|c|}{$32.3 * * *$} & \multicolumn{3}{|c|}{$42.3 * * *$} & \multicolumn{3}{|c|}{$27.9 * * *$} & \multicolumn{3}{|c|}{$37.2 * * *$} \\
\hline $\mathrm{R}^{2}$ & \multicolumn{3}{|c|}{.153} & \multicolumn{3}{|c|}{.191} & \multicolumn{3}{|c|}{.135} & \multicolumn{3}{|c|}{.135} \\
\hline
\end{tabular}


Additionally, the influence of individualism and collectivism on subjective norms, perceived control, and entrepreneurial attitude were examined using regression analysis. All of these dependencies were found to be positive and significant, thus, the results support Hypothesis 3 - both individualism and collectivism have an indirect impact on entrepreneurial intention via cognitions. However, the models explained only $10-15 \%$ of the variation.

The fourth model (cf. Liñán and Chen, 2009) assumes that the influence of attitude on intention is stronger among individualistic people, and similarly, the influence of perceived control is stronger among less individualistic people. Furthermore, the model assumes that the strength of the effect on subjective norms depends on the level of individualism. As previously described, Hypothesis 4 was examined by dividing the material on the basis of the level of individualism (see Table 5).

Table 5: The comparison between the two groups (respondents with lower levels of individualism and higher levels of individualism): Differences in means of the variables and in correlations (hypothesis 4).

\begin{tabular}{lcccccc}
\hline \multirow{2}{*}{ Variable } & \multicolumn{2}{c}{$\begin{array}{c}\text { Low level of individualism } \\
(\mathrm{N}=202)\end{array}$} & \multicolumn{2}{c}{ High level of individualism } & \multicolumn{2}{c}{ Difference } \\
& mean & $\mathrm{Sd}$ & mean & $\mathrm{Sd}$ & $\mathrm{t}$ & $\mathrm{s}$ \\
\hline Intention & 2.37 & 0.94 & 3.01 & 1.03 & -6.49 & 0.000 \\
Attitude & 3.42 & 0.60 & 3.77 & 0.72 & 5.29 & 0.000 \\
Norm & 2.64 & 0.82 & 3.15 & 0.84 & 6.09 & 0.000 \\
Control & 2.90 & 0.89 & 3.62 & 0.97 & 7.61 & 0.000 \\
\hline
\end{tabular}

\begin{tabular}{lcccccc}
\hline \multirow{2}{*}{ Relation } & \multicolumn{2}{c}{ Low level of individualism } & \multicolumn{2}{c}{ High level of individualism } & \multicolumn{2}{c}{ Difference } \\
& $\mathrm{R}$ & $\mathrm{Nig}$ & $\mathrm{R}$ & $\mathrm{sig}$ & $\mathrm{F}$ & $\mathrm{sig}$ \\
\hline Norm - attitude & 0.366 & 0.000 & 0.418 & 0.000 & 0.61 & 0.542 \\
Norm - control & 0.655 & 0.000 & 0.613 & 0.000 & 0.69 & 0.490 \\
Attitude - intention & 0.156 & 0.026 & 0.267 & 0.000 & 1.15 & 0.250 \\
Control - intention & 0.656 & 0.000 & 0.633 & 0.000 & 0.39 & 0.696 \\
\hline
\end{tabular}

The results show that entrepreneurial intentions, entrepreneurial attitudes, subjective norms, and perceived control are significantly higher among respondents with higher levels of individualism than among those with lower levels of individualism. However, the strengths of these dependencies did not differ significantly between the two groups of respondents. Thus, Hypothesis 4 has not been supported. 


\section{Discussion}

The relationship between cultural values and entrepreneurial activities is a current issue, especially in light of economic globalization. According to Liñán and Fernández-Serrano (2014), cultural and entrepreneurial factors explain a large part of the variation in gross domestic product (GDP) per capita between European countries. Also, entrepreneurship among ethnic communities (Dana, 1995; Lindsay, 2005; Kraybill, Nolt and Wesner, 2011) and some gender-specific differences in entrepreneurship (Mueller, 2004) can be explained in relation to cultural values. Individualism is a key dimension of cultural values, however, previous studies on the topic have been inconsistent.

A cross-cultural comparison based on GEM research (Xavier et al., 2013) and the individualismcollectivism index of the Hofstede Centre (2014) shows that there are some connections between individualism and entrepreneurial intentions. Entrepreneurial intention is stronger in collectivist rather than individualistic countries, although the connection is not clear-cut. In countries where individualism is horizontal in nature (e.g. the Nordic countries), entrepreneurial intention is at a low level. In contrast, in France, which is an example of vertical individualism, intention is stronger than in other developed economies in the EU. This comparison supports the explanatory model of entrepreneurship (Mueller, 2004) that combines aspects of culture with the level of economic development.

This study tested four hypotheses linked to the relationship between individualism and entrepreneurial intention. The results show, firstly, that in contrast to the assumption by Hofstede (1980), individualism and collectivism cannot be seen as extremes of the same dimension; rather, they are two separate and independent dimensions, and both have a positive effect on entrepreneurial intention. Thus, Hypothesis 1 is only partially supported. Similarly, Hypothesis 2 is only partially supported: the results suggest that vertical individualism has a positive impact on individualism, as expected; but contrary to the assumptions, the impact of horizontal individualism is also positive.

The analysis shows that a two-step model based on Ajzen's (1991, 2001) theory of planned behavior offers the best explanation of entrepreneurial intentions. Cultural values have a positive indirect impact on entrepreneurial intentions by way of subjective norms and perceived control. Thus, Hypothesis 3 has been substantiated. In contrast, the moderate model and Hypothesis 4, which is based on it, have not been supported. As expected, within the correlation coefficients, there are some differences between the two groups, but the differences are not significant. 
These results are consistent with the theory of planned behavior. Entrepreneurial intentions can be explained in relation to perceived control and subjective norms. In contrast, the dependence between entrepreneurship attitude and entrepreneurial intention is negative. This result is not completely unexpected because this study focused on general attitudes, and according to Ajzen (1991), general attitudes do not explain behavior in a specific situation. An international comparison shows that the connection between the general entrepreneurship attitude and concrete entrepreneurial intentions can even be reversed. In Finland, for example, the societal value of successful entrepreneurs is seen as the highest in the European Union, even though entrepreneurial intention is measured at a low level (Xavier et al., 2013). Therefore, the societal appreciation of entrepreneurs and entrepreneurship does not seem to affect young peoples’ willingness to become entrepreneurs.

The results show that both individualism and collectivism are significant factors in determining entrepreneurial intentions. It is plausible to think that the Individualist values, such as the highlighting of the individual autonomy and competitiveness (see. e.g. Singelis et al. 1995), are also the entrepreneurial and promote entrepreneurial intentions. On the other hand, communality creates socio-cultural capital, which can be seen as a fruitful starting point for entrepreneurship (see for instance Kraybill, Nolt and Wesner, 2011). Entrepreneurship gets various significances in individualist and collectivist cultures. For instance, Dana and Light's (2011) research reveals that Sámi people and ethnic Finns have different cultural orientations to entrepreneurship. The Finns viewed their self-employment as an individualistic form of entrepreneurship which emphasized financial capital and profit. Whereas the Sámi people who Dana and Light (2011) interviewed, emphasized the meaning of cultural tradition. In this sense, reindeer entrepreneurship is a part of cultural capital among the Sámi people, which can be passed from adults to children.

The material of this study is limited to Southern Finland in which there are neither Sámi people nor reindeer husbandry entrepreneurs. However, one can suppose that also the young people in the southern Finland, who emphasize collective values, don't assess entrepreneurship only from an economic perspective. The core of collective values consists of the family and community instead of being emphasized autonomy and competition.

Different cultural significances of the entrepreneurship must be taken into consideration also in entrepreneurship education. From this point of view, general citizenship education, which supports the development of young people's cultural values, can be seen as a significant element in entrepreneurship education (cf. Ikonen, 2006). This suggests the need for a holistic education, the aim 
of which is for individuals' autonomy and contestability to be combined with community and collective responsibility.

Conversely, according to the results, entrepreneurial intention especially depends on subjective norms and perceived control. Thus, the major challenge for entrepreneurship education is how young people's entrepreneurial readiness and self-trust in succeeding as entrepreneurs can be encouraged. According to the results, the general conception of entrepreneurship is not a major issue as such; more so, the attitudinal atmosphere within a young person's closest circle is the primary decisive factor. The key question is how we can create a positive atmosphere for entrepreneurship.

Some limitations are acknowledged in relation to the results of this study. First, the analysis is based solely on Finnish data, and the influence of cultural factors may differ between countries because of the many variations in socioeconomic factors. Therefore, the results cannot be directly generalized to other cultures. However, the main result of the study regarding the indirect impact of individualism on entrepreneurial intention has been supported by previous studies undertaken in other countries.

Second, the study is based on the concept of individualism advanced by Triandis and Gelfand (1998). Using their measure, both national and individual differences may be studied. The individual-level conception of cultural values may also be criticized. According to Schwartz (2008), cultural value orientations reflect cultures, not individuals. Culture is not always approached as a set of values or ideas, but rather as a “toolkit” or "repertoire” (Swidler, 1986). Cultural sociologists might also reject the assumption that culture generates values that drive action and they might think of culture as a set of resources that can be put to strategic use (Vaisey, 2010). However, the starting point of this study is cultural psychology where individualism and collectivism are both factors that influence individuals’ behavior and cognitions (Gorodnichenko and Roland, 2012).

A third limitation is that this study has examined only a few variables in relation to cognition. Individualism is also linked to other cognitions that influence (positively or negatively) decisionmaking in venture creation (Mitchell, 2000). Yet, overall the relationship between individualism and entrepreneurial intentions is very complex and presents a wide base that cannot be captured by a single study.

Finally, it should be noted that from the perspective of new ventures, the importance of intentions is limited. Therefore, real entrepreneurial capabilities, new business opportunities and their identification, as well as a variety of economic factors play a key role. Also, the long temporal 
distance between the time of the survey and the realization of actual behavior (new venture creation) may reduce the suitability of using intention to predict future behavior. However, such intentions are an important individual-level factor in guiding the way to a new business and are thus worthy of attention.

\section{References}

Ajzen, I. (1991). The theory planned behavior. Organizational Behavior and Human Decision Process, 50, 179-211.

Ajzen, I. (2001). Nature and Operation of Attitudes. Annual Reviews Psychology, 52, 27-58.

Armitage, C. J. \& Conner, M. (2001), “Efficacy of the Theory of Planned Behaviour: A meta analytic review”, British Journal of Social Psychology, 40 (4), 471-499.

Author(s) (2013).

Bandura, A. (1982). Self-efficacy mechanism in human agency. American Psychologist, 37, $122-147$.

City of Helsinki (2009). Nuorten koulutus Helsingissä, Tilastoja 38. Helsinki.

Chuluunbaatar, E. O., Luh, D.-B. \& Kung, S.-F. (2011). The entrepreneurial start-Up Process: The role of social capital and the social economic condition. Asian Academy of Management Journal, 16 (1), 43-71.

Dana, L-P. (1995). Entrepreneurship in a remote sub-Arctic community. Entrepreneurship Theory and Practice, 20, 57-72.

Dana,L-P. (1997). The origins of self-employment in ethno-cultural communities:

Distinguishing between orthodox entrepreneurship and reactionary enterprise. Canadian Journal of Administrative Sciences, 14 (1), 52-68.

Dana, L.-P. \& Light, I. (2011). Two forms of community entrepreneurship in Finland: Are there differences between Finnish and Sami reindeer husbandry entrepreneurs? Entrepreneurship \& Regional Development: An International Journal, 23 (5-6), 331-352.

Eagly, A. H., \& Chaiken, S. (1993). The psychology of attitudes. Fort Worth, T.X.: Harcourt Brace Jovanovich.

Fayolle, A. \& Gailly, B. (2004). Using the Theory of Planned Behaviour to Assess Entrepreneurship Teaching Programs: A First Experimentation. $14^{\text {th }}$ Annual IntEnt Conference. University of Napoli Federico II.

Fayolle, A., Gailly, B. \& Lassas-Clerc, N. (2006). Effect and Counter-effect of 
Entrepreneurship Education and Social Context on Student's Intentions. Estudiosde economia aplicada, 24 (2), 509-523.

Fayolle A. \& Liñán, F. (2014). The future of research on entrepreneurial intentions. Journal of Business Research, 67(5), 663-666.

Fitzsimmons, J. \& Douglas, E. (2005). Entrepreneurial Attitudes and Entrepreneurial Intentions: A Cross-Cultural Study of Potential Entrepreneurs in India, China, Thailand And Australia. Babson-Kauffman Entrepreneurial Research Conference, Wellesley, MA. June 2005.

Goethner, M., Obschonka, M., Silbereisen, R. K. \& Cantner, U. (2012). Scientists’ transition to academic entrepreneurship: Economic and psychological determinants. Journal of Economic Psychology, 33, 628-64.

Gorodnichenko, Y. \& Roland, G. (2012). Understanding the Individualism-Collectivism Cleavage and its Effects: Lessons from Cultural Psychology. In Aoki, M., Kuran, T. \& Roland, G. (Eds.). Institutions and Comparative Economic Development. International economics association(pp. 213-236). Palgrave Macmillan, Hampshire.

Hofstede, G. (1980). Motivation, leadership and organization: Do American theories apply abroad? Organizational Dynamic, 9 (1), 42-63.

Hofstede Centre (2014). Retrieved 25.4.2013. DOI://geert-hofstede.com.

Ikonen, R. (2006), Yrittäjyyskasvatus, Kansalaisen taloudellista autonomiaa etsimässä, SoPhi 102, Jyväskylä, Minerva

Kreiser, P., Marino,L. \& Weaver, M.K. (2001). Correlates of entrepreneurship: The impact of national culture on risk-taking and proactiveness in SMEs. University of Alabama, Department of Management and Marketing.

Krueger, N. F. JR., Reilly, M. D. \& Carsrud, A. L. (2000). Competing models of entrepreneurial intentions. Journal of Business Venturing, 15, 411-432.

Kraybill, D. B., Nolt, S. M. \& Wesner, E. J. (2011).Sources of enterprise success in Amish communities. Journal of Enterprising Communities: People and Places in the Global Economy, 5 (2), 112-130.

Lee, S. M. \& Peterson, S. (2000). Culture, entrepreneurial orientation, and global competitiveness. Journal of World Business, 35 (4), 401-416.

Liñán, F. (2008). Skill and value perceptions: how do they affect entrepreneurial intentions? International Entrepreneurship and Management Journal, 4, 257-272.

Liñán, F. \& Chen, Y.-W. (2009). Development and cross-cultural application of a specific instrument to measure entrepreneurial intentions. Entrepreneurship Theory and Practice, 33 (3), 
593-617.

Liñán, F. \& Fernandez-Serrano, J. (2014). National culture, entrepreneurship and economic development: different patterns across the European Union. Small Business Economics, 42 (4), $685-$ 701.

Liñán, F. \& Santos, F. J.(2007). Does Social Capital Affect Entrepreneurial Intentions? International Advances in Economic Research, 13:443-453.

Lindsay, N. J. (2005). Toward a cultural model of indigenous entrepreneurial attitude. Journal of the Academy of Marketing Science Review, 5, 1-17.

Lumpkin, G. T. \& Dess, G. G. (1996). Clarifying the entrepreneurial orientation construct and linking it to performance. Academy of Management. The Academy of management review, 21 (1), 135-172.

Ministry of education (2004). Opetusministeriön yrittäjyyskasvatuksen linjaukset ja toimenpideohjelma. Opetusministeriön julkaisuja 2004: 18. Koulutus- ja tiedepolitiikan osasto. . www.minedu.fi/export/sites/default/OPM/Julkaisut/2004/liitteet/opm_169_opm18.pdf?lang=fi.

Ministry of Employment and the Economy (2012).Yrittäjyyskatsaus 2012. Työ- ja elinkeinoministeriön julkaisuja. Työ ja yrittäjyys. 46/2012.

Mitchell, R.K., Smith, B., Seawright, K., \& Morse, E.A. (2000). Cross-cultural cognitions and venture creation: decision. Academy of Management Journal, 43, 974-993.

Moriano, J. A., Gorgievski, M. Laguna, M. Stephan ,U. \& Zarafshani,K. (2012). A CrossCultural Approach to Understanding Entrepreneurial Intention. Journal of Career Development, 39 (2), 162-185.

Mueller, S.L. (2004), Gender Gaps in Potential for Entrepreneurship A cross Countries and Cultures. Journal of developmental entrepreneurship, 9 (3), 199-220.

Mueller, S.L. \& Thomas, A.S. (2001) Culture and entrepreneurial potential: A nine country study of locus of control and innovativeness. Journal of Business Venturing, 16 (1), 51-75.

Noorderhaven, N., Thurik, R., Wennekers, S. \& van Stel, A. (2004) The Role of Dissatisfaction and per Capita Income in Explaining Self-Employment across 15 European Countries. Entrepreneurship Theory and Practice. 28, 447-466.

Official Statistics of Finland (OSF): Annual national accounts [e-publication]. ISSN=1798-0623. Helsinki: Statistics Finland [referred: 16.4.2014].

Access method: http://tilastokeskus.fi/til/vtp/tau_en.html.

Rantanen, T. \& Toikko, T. (2013a). Scandinavian social values, attitudes and young people’s entrepreneurial attitudes. USA-China Business Review, 12(4), 349-360.

Rantanen, T. \& Toikko, T. (2013b). Social values, societal entrepreneurship attitudes, and 
entrepreneurial intention of young people in the Finnish welfare state. Poznan University of Economics Review, 13(1), 8-25.

Schimmack, U., Oishi,S. \& Diener, E. (2005). Individualism: A valid and important dimension of cultural differences between nations. Personality and Social Psychology Review, 9 (1), 17-31.

Singelis, T. M., Triandis, H. C., Bhawuk, D. P. S. \& Gelfand, M. J. (1995). Horizontal and vertical dimensions of individualism and collectivism: A theoretical and measurement refinement. Cross-Cultural Research, 29, 240-275.

Siu, W.-S. \& Lo, E. S.-C. (2013). Cultural Contingency in the Cognitive Model of Entrepreneurial Intention. Entrepreneurship Theory and Practice, 37(2), 147-173.

Schwartz, S. H. (2008), Cultural Value Orientations: Nature \& Implications of National Differences, Israel Science Foundation, Jerusalem.

Swidler, A. (1986). Culture in action: Symbols and strategies. American Sociological Review, 51 (2), 273-286.

Tiessen, J.H. (1997). Individualism, collectivism, and entrepreneurship: A framework for international comparative research. Journal of Business Venturing, 12, 367-384.

Triandis, H. C. \& Gelfand, M. J. (1998). Converging Measurement of Horizontal and Vertical Individualism and Collectivism. Journal of Personality and Social Psychology, 74 (1), 118-128.

Urban, B. (2004) Understanding the moderating effect of culture and self-efficacy on entrepreneurial intentions. University of Pretoria. Department of business management.

Vaisey, S. (2010). What people want: Rethinking poverty, culture, and educational attainment. The ANNALS of the American Academy of Political and Social Science, 629, 75-101.

Walker, J. K., Jeger, M. \& Kopecki, D. (2013). The Role of Perceived Abilities, Subjective Norm and Intentions in Entrepreneurial Activity. The Journal of Entrepreneurship, 22 (2), 181-202.

Weaver, K. M., Liguori, E. W., Hebert, K. \& Vozikis, G. S. (2012). Building Leaders in Secondary Education: An Initial Evaluation of an Entrepreneurial Leadership Development Program. Journal of Higher Education Theory and Practice, 12 (1), 19-26.

Xavier, S. R., Kelley, D., Kew, J., Herrington, M. \& Vorderwulbecke, A. (2013). Global entrepreneurship monitor 2012 Global Report. Babson, Universidad del Desarroll0 \& University Tun Abdul Razak. GEM. 